\title{
Identification of potential markers for type 2 diabetes mellitus via bioinformatics analysis
}

\author{
YANA LU ${ }^{1}$, YIHANG LI ${ }^{1}$, GUANG LI ${ }^{1 *}$ and HAITAO LU ${ }^{2 *}$ \\ ${ }^{1}$ Key Laboratory of Dai and Southern Medicine of Xishuangbanna Dai Autonomous Prefecture, Yunnan Branch, \\ Institute of Medicinal Plant Development, Chinese Academy of Medical Sciences and Peking Union Medical College, \\ Jinghong, Yunnan 666100; ${ }^{2}$ Key Laboratory of Systems Biomedicine, Shanghai Center for Systems Biomedicine, \\ Shanghai Jiao Tong University, Shanghai 200240, P.R. China
}

Received March 20, 2019; Accepted January 20, 2020

DOI: $10.3892 / \mathrm{mmr} .2020 .11281$

\begin{abstract}
Type 2 diabetes mellitus (T2DM) is a multifactorialand multigenetic disease, and its pathogenesis is complex and largely unknown. In the present study, microarray data (GSE201966) of $\beta$-cell enriched tissue obtained by laser capture microdissection were downloaded, including 10 control and 10 type 2 diabetic subjects. A comprehensive bioinformatics analysis of microarray data in the context of protein-protein interaction (PPI) networks was employed, combined with subcellular location information to mine the potential candidate genes for T2DM and provide further insight on the possible mechanisms involved. First, differential analysis screened 108 differentially expressed genes. Then, 83 candidate genes were identified in the layered network in the context of PPI via network analysis, which were either directly or indirectly linked to T2DM. Of those genes obtained through literature retrieval analysis, 27 of 83 were involved with the development of T2DM; however, the rest of the 56 genes need to be verified by experiments. The functional analysis of candidate genes involved in a number of biological activities, demonstrated that 46 upregulated candidate genes were involved in 'inflammatory response' and 'lipid metabolic process', and 37 downregulated candidate genes were involved in 'positive regulation of cell death' and 'positive regulation of
\end{abstract}

Correspondence to: Dr Guang Li, Key Laboratory of Dai and Southern Medicine of Xishuangbanna Dai Autonomous Prefecture, Yunnan Branch, Institute of Medicinal Plant Development, Chinese Academy of Medical Sciences and Peking Union Medical College, 138 Xuanwei Road, Jinghong, Yunnan 666100, P.R. China

E-mail: lhbg311@hotmail.com

Professor Haitao Lu, Key Laboratory of Systems Biomedicine, Shanghai Center for Systems Biomedicine, Shanghai Jiao Tong University, 800 Dongchuan Road, Minxing, Shanghai 200240, P.R. China

E-mail: haitao.lu@sjtu.edu.cn

Key words: type 2 diabetes, differentially expressed genes, functional analysis, protein-protein interaction, subcellular location, transcription factors, microRNA cell proliferation'. These candidate genes were also involved in different signaling pathways associated with 'PI3K/Akt signaling pathway', 'Rap1 signaling pathway', 'Ras signaling pathway' and 'MAPK signaling pathway', which are highly associated with the development of T2DM. Furthermore, a microRNA (miR)-target gene regulatory network and a transcription factor-target gene regulatory network were constructed based on miRNet and NetworkAnalyst databases, respectively. Notably, hsa-miR-192-5p, hsa-miR-124-5p and hsa-miR-335-5p appeared to be involved in T2DM by potentially regulating the expression of various candidate genes, including procollagen C-endopeptidase enhancer 2, connective tissue growth factor and family with sequence similarity 105 , member $\mathrm{A}$, protein phosphatase 1 regulatory inhibitor subunit $1 \mathrm{~A}$ and $\mathrm{C}-\mathrm{C}$ motif chemokine receptor 4. Smad5 and Bcl6, as transcription factors, are regulated by ankyrin repeat domain 23 and transmembrane protein 37 , respectively, which might also be used in the molecular diagnosis and targeted therapy of T2DM. Taken together, the results of the present study may offer insight for future genomic-based individualized treatment of T2DM and help determine the underlying molecular mechanisms that lead to T2DM.

\section{Introduction}

Type 2 diabetes mellitus (T2DM) has become the third main chronic non-infectious disease following tumors and cardiovascular disease, and threatens human health worldwide (1). In total, 425 million adults are currently living with diabetes in the world, with the majority of cases being T2DM (2). The International Diabetes Federation reported that in 2045, 629 million individuals globally will suffer from diabetes, of which $\sim 90 \%$ will be T2DM (2). It is well known that insulin resistance and pancreatic $\beta$-cell dysfunction are major pathophysiological characteristics of T2DM. Pancreatic $\beta$-cells are needed to yield more insulin to meet mounting requirements when insulin resistance occurs (3). Previous studies of pancreatic $\beta$-cells provide a basis for improved insight into the pathogenesis and pathophysiology of T2DM, as pancreatic $\beta$-cells help in the regulation of the blood glucose level $(4,5)$. T2DM is a complex, polygenic disease that results from the interplay of environmental and genetic factors. Candidate gene 
association high-throughput methods have been carried out to uncover the genetic aspects of the pathogenesis of T2DM (6-8).

In recent years, single gene research and genome-wide association studies have determined genetic susceptibility genes for the increased risk of T2DM (9-11). Previous studies of gene expression in T2DM demonstrated that decreased expression of insulin $(12,13)$, and a reduced expression of syntaxin $1 \mathrm{~A}$ and transcription factor 7 like 2 contributed to impaired insulin secretion $(12,14,15)$. The downregulation of FXYD domain containing ion transport regulator 2-stimulated $\beta$-cell proliferation (13) and the upregulation of genes $\delta$ like non-canonical Notch ligand 1 , diacylglycerol kinase $\beta$ and zinc finger MIZ-type containing 1 were implicated in T2DM $(11,16)$. Previous genetic studies identified several dozen genes leading to monogenic diabetes due to impaired insulin secretion $(17,18)$. These genes play a key role in pancreatic $\beta$-cell lineage, phenotype and function. How genetic and epigenetic factors are involved in $\beta$-cell development, proliferation, differentiation and function requires further investigation. Understanding of the underlying mechanisms is vital to the development of new therapeutic methods to prevent $\beta$-cell dysfunction and failure in the development of T2DM. The identification of T2DM candidate genes has been challenging in biomedical research and the majority of the genes have yet to be discovered. The aim of the present study was to contribute to research efforts to identify the biological markers and signaling pathways associated with T2DM. These molecular mechanisms may provide insight for aspects of T2DM pathogenesis or pathophysiology.

High-throughput sequencing is becoming an important tool, extensively applied in life sciences, including in cancer detection (19-21) and for identifying global gene expression changes in T2DM (22). Knowledge of the subcellular localization of proteins provides new insight into protein function and the complex pathways that modulate biological processes on a sub-cellular level, contributing to the current understanding of the proteins that interact with each other and with other molecules in the cellular environment (23). Accordingly, subcellular proteomics, as an important step to functional proteomics, has been the focus of the prediction of subcellular protein location, which is associated with molecular cell biology, proteomics, systems biology and drug discovery (24-26); it is used to better understand complex diseases (27), such as breast cancer (28), ovarian carcinoma (29), ischemic dilated cardiomyopathy (30), esophageal squamous cell carcinoma (31) and asthma (32). It was previously demonstrated that an integrative analysis of gene expression and a protein-protein interaction (PPI) network could offer insight of the molecular mechanisms of a variety of diseases (33-35). Consequently, the present study proposed a comprehensive bioinformatics analysis of gene expression data combining protein subcellular localization information and the construction of a layered PPI network (as opposed to a traditional PPI network) to identify candidate genes. Functional enrichment analyses were performed for candidate genes. A microRNA (miRNA/miR)-target gene regulatory network and transcription factor (TF)-target gene regulatory network were also constructed to identify miRNAs and TFs, which could be involved in T2DM development. The findings of the present study may help in the discovery of potentially novel predictive and prognostic markers for T2DM, and provide insight into the underlying molecular mechanisms of T2DM.

\section{Materials and methods}

Data acquisition, preprocessing and differentially expressed genes (DEGs) analysis. GSE20966 (36), the gene chip datasets of $\beta$-cells acquired from cadaver pancreases of non-diabetic subjects (control group, $\mathrm{n}=10$ ) and T2D subjects (T2D group, $\mathrm{n}=10$ ), was assessed and obtained from the Gene Expression Omnibus database (http://www.ncbi.nlm.nih.gov/geo/). The annotation information of GeneChip was acquired from the GPL1352 Affymetrix Human X3P Array platform (Affymetrix; Thermo Fisher Scientific, Inc.). The probes were mapped to gene names based on the GPL1352 platform and the average expression value for the probes was calculated when there was more than one gene corresponding to the same probe. In the original gene expression profiles, after normalization, MATLAB 2018a (https://www.ilovematlab.cn/forum.php?mod=home) was used to identify the DEGs by value of a fold change $>1.5$ and a false discovery rate_Benjamini \& Hochberg $\left(\mathrm{fdr} \_\mathrm{BH}\right)<0.1$. The differences in gene expression between the control and T2DM subjects were assessed using hierarchical clustering and principal component analysis (PCA).

PPI network, layering and network analysis. The PPI data were retrieved from the Human Protein Reference Database v9.0 (HPRD) (37), BioGRID v3.5 (38), IntACT v4.2 (39) and STRING v10.5 (40) databases. First, single nodes, self-loops and duplicates were removed from the PPI data. Second, the total DEGs were mapped to the PPI data. To improve the reliability, only the direct interaction proteins of these DEGs were matched. Third, the integrated PPI network was visualized and analyzed using Cytoscape v3.6.1 (41). Then, the subcellular localization information for each protein in the integrated PPI network obtained from the HPRD, the UniProt database (http://www.uniprot.org/help/uniprotkb) and the Human Protein Atlas database (http://www.proteinatlas.org/) (42) was input as a node attribute. The Cerebral plug-in in Cytoscape was applied to redistribute nodes on the basis of subcellular localization without changing their interactions (43). The layered PPI network was split into five layers: Extracellular, plasma membrane, cytoplasm, nucleus and mitochondria. Hub protein nodes that encoded DEGs in the layered network with a connectivity degree $>8$ were screened as candidate genes.

Functional interpretations for the candidate genes. To investigate the functions of the candidate genes, functional enrichment analysis was performed using the ClueGO and the CluePedia plug-ins (44) for Cytoscape v3.6.1 software (45). ClueGO was used to decipher functionally grouped Gene Ontology (GO) (46) and pathway annotation networks to understand their implication in three different classifications; biological process (BP), molecular function (MF) and cell component (CC), in addition to the Kyoto Encyclopedia of Genes and Genomes (KEGG) (47) signaling pathway. The relationship between the terms was calculated using $\kappa$ statistics and the ClueGO network was built based on the similarity of their related genes. The CluePedia plug-in is a search tool for new markers potentially associated to pathways, and can provide a broad viewpoint of a pathway using integrated experimental and in silico data. In the present study, the enrichment analysis of gene-BP and gene-pathway was 
Table I. Distribution of nodes.

\begin{tabular}{lrcrr}
\hline Localization & Upregulated & Downregulated & Unchanged & Total \\
\hline Extracellular & 13 & 5 & 132 & 150 \\
Plasma membrane & 7 & 9 & 244 & 260 \\
Cytoplasm & 21 & 8 & 427 & 456 \\
Nucleus & 8 & 14 & 516 & 538 \\
Mitochondrion & 3 & 0 & 139 & 142 \\
Total & 52 & 36 & 1,458 & 1,546 \\
\hline
\end{tabular}

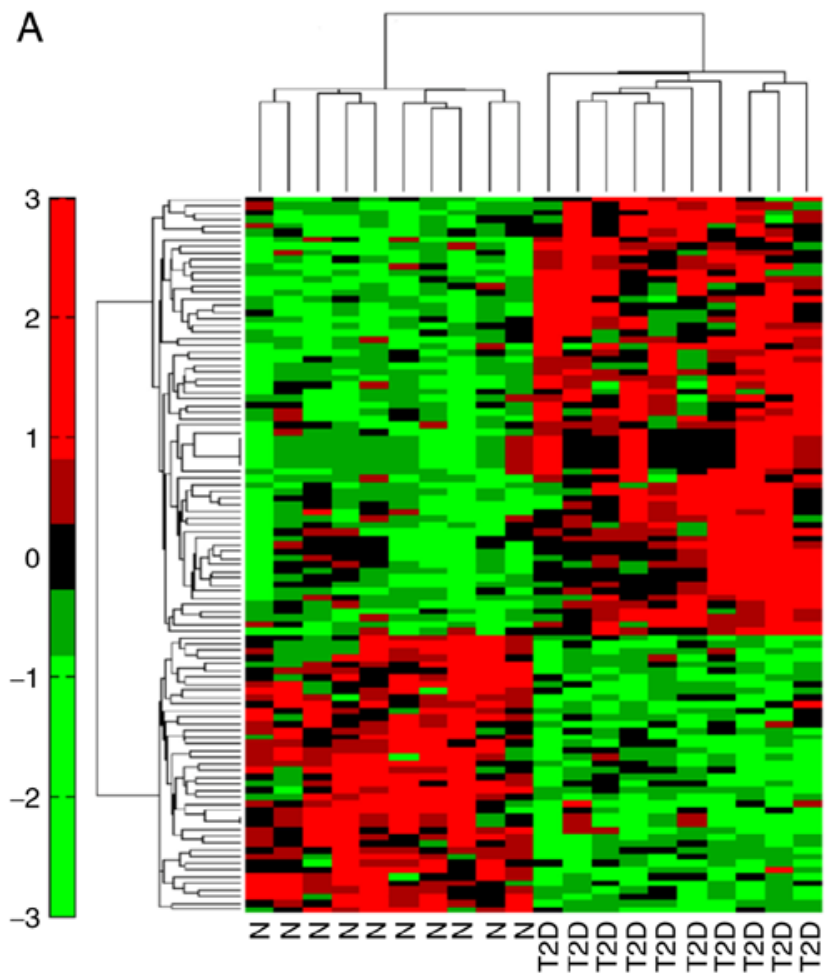

B

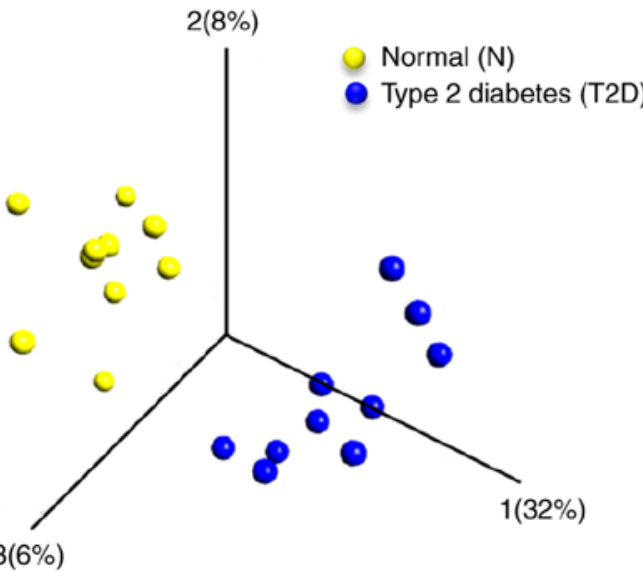

Figure 1. Hierarchical clustering and principal component analysis of DEGs between control and T2DM subjects. (A) Hierarchical clustering analysis of DEGs was performed using MATLAB software, which split samples into groups with similar models in gene expression data. Red represents upregulated genes and green represents downregulated genes. (B) Principal component analysis of control and T2DM subjects based on DEGs. Yellow dots and blue dots refer to controls and T2DM subjects, respectively. DEGs, differentially expressed genes; T2DM; type 2 diabetes mellitus.

statistically validated using the Cytoscape plug-ins ClueGO and CluePedia. BPs/signaling pathways were functionally split into several groups with $\kappa$ score $\geq 0.4$ and a network was constructed, where the node represents a $\mathrm{BP} /$ pathway and the edge between two nodes indicates that the two BPs/pathways share common genes.

Prediction of target miRNAs and TFs for the candidate genes. Genes need to interact to react to the environment of an organism, as they cannot alone to regulate the organism. Gene expression is modulated by TFs and miRNAs at the transcriptional and post-transcriptional levels. Information on TFs, miRNAs and their corresponding target genes could provide insight into the processes of T2DM. miRNet v2.0 (http://www. mirnet.ca/) (48) was used to predict the miRNAs associated with candidate genes noted in miRTarBase v7.6 (49) and miRecords (50). The 8 most captivating groups (top 15) and a minimum of two genes for each of the groups were picked as the threshold. Then, the TFs encoded by candidate genes were used for prediction coupled with human TF information (NetworkAnalyst v3.0; http://www.net workanalyst.ca) (51) noted in Binding and Expression Target Analysis v1.0.7 (BETA) (http://cistrome.org/BETA/) (52). The miRNA-target gene regulatory network and TF-target gene regulatory network were visualized using Cytoscape.

\section{Results}

Screening for DEGs. Following data preprocessing, 108 DEGs were identified to be differentially expressed in 10 control subjects and 10 T2DM subjects, with 66 upregulated and 42 downregulated genes, as presented in the heat map of the cluster analysis of DEGs, according to the cut-off criteria of fold change $>1.5$ and fdr_BH $<0.1$ (Fig. 1A; Table SI). 


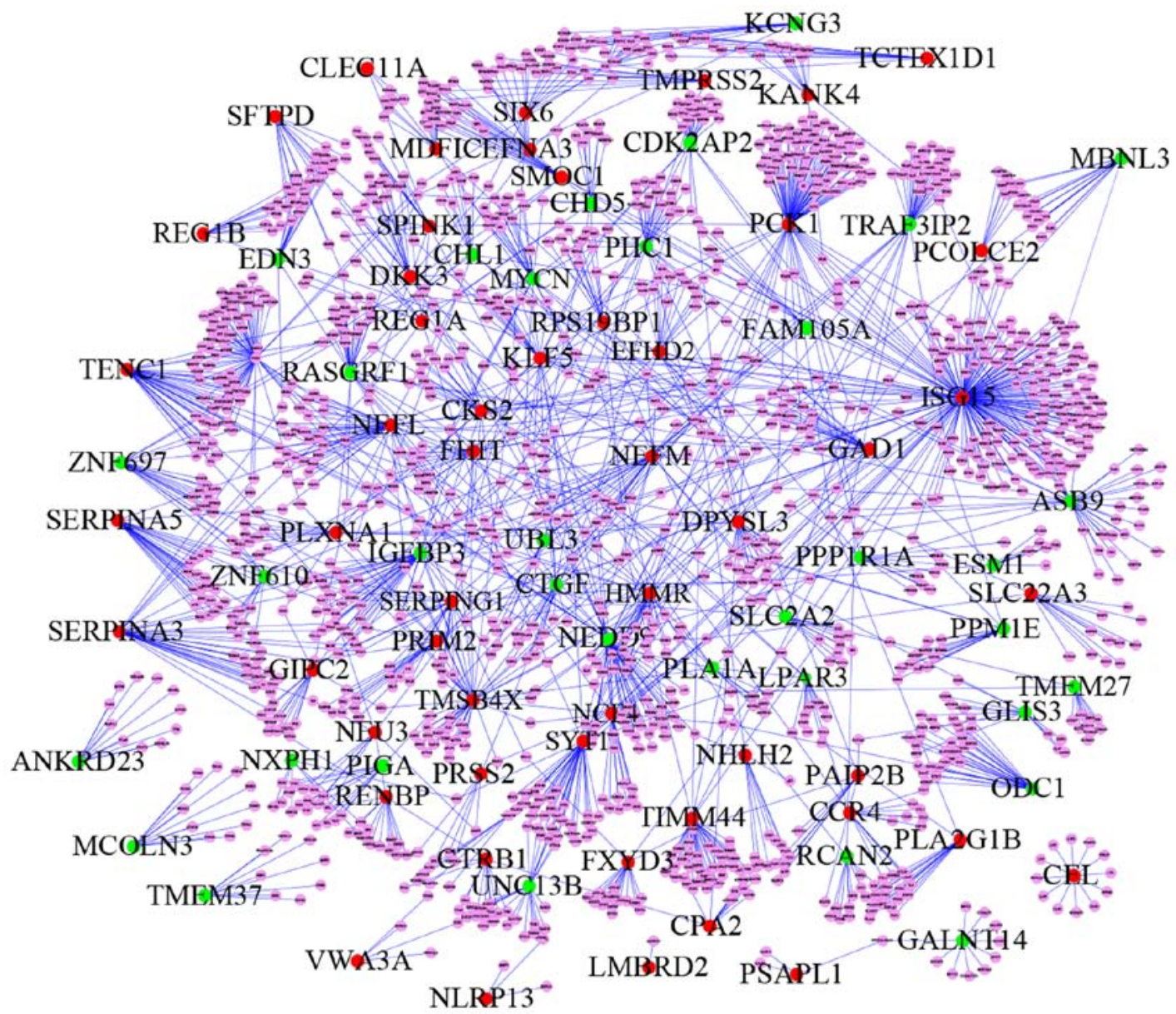

Figure 2. Integrated protein-protein interaction network. Different color nodes represent the proteins that were encoded by differentially expressed genes. Red nodes are proteins that encoded upregulated genes and the green nodes are proteins that encoded downregulated genes. Pink nodes are proteins that were not encoded by significant differentially expressed genes.

CTRB1 . CTGE... - . - PLA.... - PLA NXPHEERPINA3
$\because$ CEE: TMEM27 27 NEU3 EFNAFAR

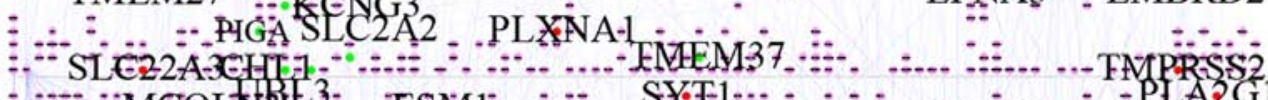

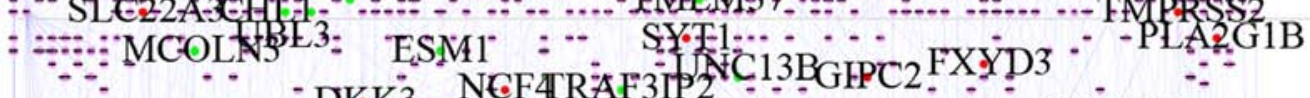

\section{DKK3, NGF4RAF3IP2, RENBP}
RASGRF1 :
$-\mathrm{TMSB̈} 4 \mathrm{X}$
Cytoplasm

TENE1 PSAPED ODECDPXSI:

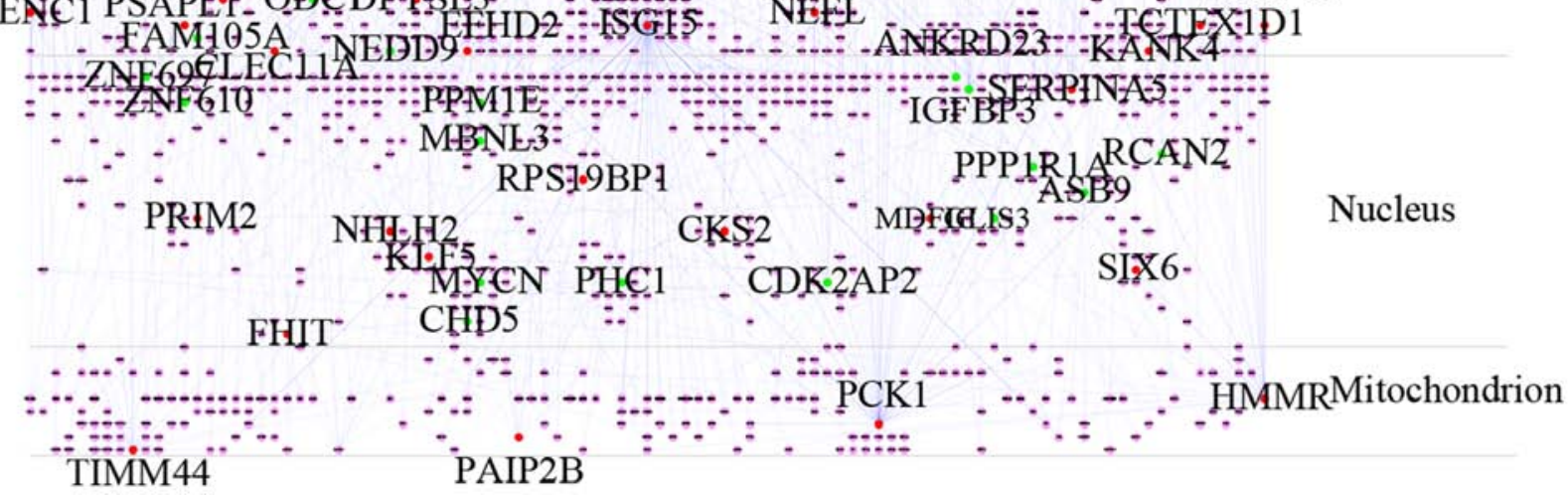

Figure 3. Layered protein-protein interaction network. Red nodes are upregulated genes, green nodes are downregulated genes and pink nodes are unchanged genes. 
Table II. Topological parameters of network.

\begin{tabular}{lc}
\hline Parameters & Value \\
\hline $\mathrm{y}=\beta \mathrm{x}^{\alpha}$ & $\mathrm{y}=73.313 \mathrm{x}^{-1.347}$ \\
$\mathrm{R}^{2}$ & 0.865 \\
Correlation & 0.946 \\
Clustering coefficient & 0.2 \\
Network centralization & 0.118 \\
Network density & 0.002 \\
\hline
\end{tabular}

The PCA plot demonstrated that the DEGs could roughly divide the majority of T2DM subjects from the non-diabetic controls (Fig. 1B).

PPI network, layering network construction and network analysis. The identification of proteins that interact directly with proteins encoded by the 108 DEGs could help understand the molecular mechanism underlying T2DM pathophysiology. In the present study, a PPI network was built from the 108 DEGs with Cytoscape and was composed of 1,546 nodes and 1,842 edges, including 52 proteins that were encoded by upregulated genes, 36 that were encoded by downregulated genes and 1,458 nodes marking proteins that were not encoded by DEGs (Fig. 2; Table I).

Subcellular protein localization is a crucial process in numerous cells. Following synthesis, proteins are transported to distinct compartments depending on their molecular function within the cell. Certain proteins are even transported to distant sites. Protein localization data can contribute to the elucidation of protein functions. The subcellular localization information for each protein in the integrated PPI network obtained from the HPRD, the UniProt database (http://www. uniprot.org/help/uniprotkb) and the Human Protein Atlas database (http://www.proteinatlas.org/) (42), was input as a node attribute. Then, the layered network was created from the PPI network using the Cerebral plug-in (43) of Cytoscape, according to the subcellular localization information of 1,546 proteins, which was split into five layers as follows: Extracellular, plasma membrane, cytoplasm, nucleus and mitochondrion (Fig. 3).

The degree distribution of a network is a standard feature of scale-free networks. The degree distributions of the layered network closely followed the power law distribution, with an $\mathrm{R} 2=0.865$. This suggested that the integrated PPI network is a true cellular complex biological network and scale-free. The other topological parameters of the network are presented in Table II. The results also suggested that a small number of nodes are hubs with a number of links to nodes. A total of 83 DEGs were identified as hub genes with an interaction degree $\geq 8$ and were selected as candidate genes (Table SII). The top 20 candidate genes are presented in Table III. Of these candidate genes, ISG15 ubiquitin like modifier (ISG15) had the highest degree (185), followed by phosphoenolpyruvate carboxykinase 1 (PCK1) (85) and neural precursor cell expressed, developmentally downregulated 9 (NEDD9) (50). The present study identified 83 candidate genes for T2DM (Table IV). The identified candidate genes may serve as biological markers for future T2DM treatment research.
Table III. Top 20 hub genes.

\begin{tabular}{llcc}
\hline No. & Gene name & Degree & Gene expression \\
\hline 1 & ISG15 & 185 & Upregulated \\
2 & PCK1 & 85 & Upregulated \\
3 & NEDD9 & 50 & Downregulated \\
4 & TMSB4X & 44 & Upregulated \\
5 & SYT1 & 44 & Upregulated \\
6 & IGFBP3 & 41 & Downregulated \\
7 & NEFL & 41 & Upregulated \\
8 & TENC1 & 37 & Upregulated \\
9 & TIMM44 & 36 & Upregulated \\
10 & HMMR & 35 & Upregulated \\
11 & ASB9 & 34 & Downregulated \\
12 & TRAF3IP2 & 34 & Downregulated \\
13 & KLF5 & 32 & Upregulated \\
14 & SERPINA3 & 31 & Upregulated \\
15 & NEFM & 30 & Upregulated \\
16 & PHC1 & 29 & Downregulated \\
17 & RASGRF1 & 29 & Downregulated \\
18 & SERPING1 & 28 & Upregulated \\
19 & MYCN & 27 & Downregulated \\
20 & SERPINA5 & 26 & Upregulated \\
\hline & & &
\end{tabular}

Functional enrichment analysis. To clarify possible biological functions of candidate genes, and examine the relationship between the functional groups and their underlying annotations in the networks, BP enrichment analyses were performed for the 46 upregulated and 37 downregulated candidate genes using ClueGO and CluePedia. A $\kappa$ score $>0.4$ was set as the criterion. The results are presented in Fig. 4. Specifically, for the upregulated groups, the results yielded BPs related to the activation of 'cellular response to cytokine stimulus', 'chemotaxis', 'inflammatory response', 'lipid metabolic process', 'macromolecule catabolic process', 'positive regulation of biosynthetic process', 'neurogenesis', 'regulation of cell differentiation', 'regulation of peptidase activity', 'regulation of transport', 'response to external biotic stimulus' and 'response to wounding' (Fig. 4A). For the downregulated groups, the results yielded BPs related to the activation of 'ion transport', 'neuron differentiation', 'positive regulation of cell death', 'positive regulation of cell proliferation', 'positive regulation of cellular component biogenesis', 'positive regulation of signaling', 'regulation of cell cycle process' and 'regulation of ion transport' (Fig. 4B).

To obtain an improved understanding of the functional involvement of these candidate genes, pathway-based functional enrichment analyses was performed using ClueGO and CluePedia. A $\kappa$ score $>0.4$ was set as the criterion. These genes were involved in pathways associated with 'amyotrophic lateral sclerosis (ALS)' [neurofilament light (NEFL) neurofilament medium], 'axon guidance' [ephrin A3 (EFNA3) and plexin A1 (PLXNA1)], 'cellular senescence' [insulin like growth factor binding protein 3 (IGFBP3) and TRAF3 interacting protein 2 (TRAF3IP2)], 'complement and coagulation cascades' [serpin family A member 5 (SERPINA5) and serpin family 
Table IV. Candidate gene identification for type 2 diabetes mellitus.

A, Upregulated genes, $n=46$

\begin{tabular}{ll}
\hline Gene name & PIMID \\
\hline
\end{tabular}

\begin{tabular}{lr}
\hline$C C R 4$ & PMID: 17244154, PMID: 12464673 \\
$C E L$ & PMID: 19760265 \\
$C K S 2$ & \\
$C P A 2$ & \\
$C T R B 1$ &
\end{tabular}

DKK3

DPYSL3

EFHD2

EFNA3

FHIT

FXYD3

GADI

GIPC2

HMMR

ISG15

KANK4

KLF5

MDFIC

NCF 4

NEFL

NEFM

NEU3

NHLH2

PAIP2B

PCK 1

PLA2G1B

PLXNAI

PRIM2

PRSS2

REG1A

REGIB

RENBP

RPS19BP1

SERPINA3

SERPINA5

SFTPD

SIX6

SLC22A3

SMOC1

SPINK1

SYT1

TCTEX1D1

TENC1

TIMM44

TMPRSS2

TMSB $4 X$

PMID: 25031023

PMID: 17292733

PMID: 16567514

PMID: 28150914

PMID: 23478426

PMID: 28163738

PMID: 15144884

PMID: 25749183
Table IV. Continued.

B, Downregulated, $n=37$

\begin{tabular}{lc}
\hline Gene names & PIMID \\
\hline SERPING1 & PMID: 23277452 \\
ANKRD23 & PMID: 26398569 \\
ASB9 & \\
CDK2AP2 & \\
CHD5 &
\end{tabular}

CHL1

PMID: 22768844

CTGF

PMID: 22045431

EDN3

ESM1

PMID: 27756187

FAM105A

PMID: 20644627

GALNT14

GLIS3

PMID: 23737756

IGFBP3

KCNG3

LPAR3

$M B N L 3$

MCOLN3

$M Y C N$

NEDD9

NXPH1

ODC 1

PCOLCE2

PHC1

PIGA

PLAIA

PPMIE

PMID: 20801214

PPPIRIA

PMID: 25489054

RASGRF 1

RCAN2

SLC2A2

PMID: 28052964

TMEM27

PMID: 24905913

TMEM37

PMID: 29185012

TRAF3IP2

PMID: 23085260

$U B L 3$

UNC13B

ZNF610

ZNF697

PIMID, PubMed number.

G member 1 (SERPING1)], 'fat digestion and absorption' [carboxyl ester lipase $(C E L)$ and phospholipase A2 group IB $(P L A 2 G 1 B)$ ], 'glucagon signaling pathway' ( $P C K 1$ and solute carrier family 2 member 2 ), 'influenza A' [serine protease 2 (PRSS2) and transmembrane serine protease 2 (TMPRSS2)], 
'MAPK signaling pathway' [EFNA3 and Ras protein specific guanine nucleotide releasing factor $1(R A S G R F 1)]$, 'neuroactive ligand-receptor interaction' [lysophosphatidic acid receptor 3 (LPAR3) and PRSS2], 'PI3K-Akt signaling pathway' (EFNA3, LPAR3 and PCK1), 'pancreatic secretion' [CEL, carboxypeptidase A2 (CPA2), chymotrypsinogen B1 (CTRBI), $P L A 2 G 1 B$ and PRSS2], 'pathways in cancer' [CDC28 protein kinase regulatory subunit 2 (CKS2) and LPAR3), "phagosome' [neutrophil cytosolic factor 4 (NCF4) and surfactant protein D (SFTPD)], 'protein digestion and absorption' (CPA2, $C T R B 1$ and PRSS2), 'purine metabolism' [fragile histidine triad diadenosine triphosphatase (FHIT) and DNA primase subunit 2), 'Rap1 signaling pathway' (EFNA3 and LPAR3), 'Ras signaling pathway' (EFNA3, phospholipase A1 member A, PLA2G1B and RASGRF1), 'small cell lung cancer' (CKS2 and FHIT), 'synaptic vesicle cycle' [synaptotagmin $(S Y T I)$ and unc-13 homolog B (UNC13B)] and 'transcriptional misregulation in cancer' (IGFBP3, MYCN proto-oncogene, bHLH transcription factor and TMPRSS2) (Fig. 5).

miRNA-target gene regulatory network. The miRNAs for DEGs were predicted using the two microRNA prediction tools through miRNet. The miRNA-gene regulatory network was built, which included 22 upregulated target genes, 19 downregulated target genes and 12 miRNAs (Fig. 6). A total of 12 miRNAs were selected, including hsa-mir-335-5p (degree $=15$ ), hsa-mir-8485 $($ degree $=4)$, hsa-mir-1277-5p (degree $=5)$, hsa-mir-190a-3p (degree $=5)$, hsa-mir-5011-5p (degree=5), hsa-mir-124-3p (degree=6), hsa-mir-7106-5p (degree $=5)$, hsa-let-7a-5p (degree=5), hsa-mir-192-5p (degree=5), hsa-mir-26b-5p (degree=6), hsa-let-7b-5p (degree=5) and hsa-mir-98-5p (degree=5).

TF-target gene regulatory network. In order to understand the topology and dynamics of the transcriptional regulatory network, TFs with a $\mathrm{P}<0.05$ in BETA with its target genes via network analysis were built into a TF-target gene regulatory network using Cytoscape. The network consisted of 127 edges and 66 nodes (Fig. 7). Based on the degree, the top 8 TFs were selected to be enhancers of SUZ12 polycomb repressive complex 2 subunit (SUZ12; degree=10), enhancer of zeste 2 polycomb repressive complex 2 subunit $(E Z H 2$; degree $=15)$, BCL6 transcription repressor $(B C L 6$; degree $=9)$, zinc finger protein 580 (ZNF580; degree=10), Kruppel like factor 9 (KLF9; degree $=8)$, MYC associated zinc finger protein $(M A Z$; degree $=15)$, activating transcription factor 1 (ATF1; degree $=12)$, structure specific recognition protein 1 (SSRPI; degree $=10)$, WRN helicase interacting protein 1 (WRNIPI; degree $=10$ ), chromodomain helicase DNA binding protein 1 $(C H D 1$; degree $=10)$ and SMAD5 (degree=11).

\section{Discussion}

T2DM is a multifactorial and multigenetic disease, and its pathogenesis is complex and largely unknown. A PPI network and a layered network for DEGs were constructed and it was observed that the majority of the proteins were localized in the cytoplasm, followed by the nucleus. The modules were mined from the PPI network and ISG15, PCKI, NEDD9, thymosin $\beta 4 \mathrm{X}$-linked (TMSB $4 X$ ), SYT1, IGFBP3, NEFL, tensin 2, translocase of inner mitochondrial membrane 44
(TIMM44), hyaluronan mediated motility receptor (HMMR), ankyrin repeat and SOCS box containing 9 and TRAF3IP2 were screened as the candidate genes with the highest degree of connectivity.

ISG15 has an anti-apoptotic capability on MIN6 cells (53). Upregulated $I S G 15$ could be a potential therapeutic approach for type 1 diabetes (T1D) in pancreatic $\beta$-cells (53). PCK1 has been a candidate gene for T2DM susceptibility (54). SYT1 is a $\mathrm{Ca}^{2+}$ sensor that plays a central role in insulin release, which is a characteristic deterioration in the early stages of T2DM $(55,57)$. Higher levels of IGFBP3 might raise the risk of T2DM $(57,58)$. The TIMM44 gene could be a new target for T2DM therapy (59). The procession of vascular diseases can be delayed by targeting TRAF3IP2 during diabetes and atherosclerosis, as TRAF3IP2 reconciles high glucose-induced NF- $\mathrm{KB}$ and AP-1-dependent inflammatory signaling and endothelial dysfunction (60). TRAF3IP2 may play a role in the pathogenesis of T1D (61). Notably, to the best of the authors' knowledge, ribosomal protein S19 binding protein 1 (RPS19BPI) and SFTPD have not been previously reported to be dysregulated in T2DM. $R P S 19 B P 1$ is a direct regulator of NAD-dependent deacetylase sirtuin-1 (SIRT1), which is a promising molecular target for the treatment of obesity. RPS19BPI can serve as a prognostic indicator via the direct regulation of SIRT1 in obese patients with T2DM (62-64). SFTPD is an element of lung innate immunity that strengthens pathogen clearance and regulates inflammatory responses (65); its expression is decreased in obesity and in impaired glucose tolerance, both of which are related to the development of T2DM.

The functional assay for candidate genes using ClueGO and CluePedia in GO terms or KEGG pathways identified several molecular mechanisms, widely known to underlie the pathogenesis of T2DM. A number of vital processes/signaling pathways and key factors connected with the pathogenesis of T2DM were identified from the functional enrichment analyses. In the upregulated group, a number of the corresponding encoded proteins were distributed in the extracellular and cytoplasmic layers. In particular, it was identified that the majority of BPs were associated with 'inflammatory response', 'cellular response to cytokine stimulus' and 'lipid metabolic process'. In previous years, a number of studies have suggested that T2DM may be a chronic inflammatory response modulated by inflammatory factors (66-69). Immune cell infiltration and high levels of cytokines were observed in the pancreas islets of T2DM (70,71), which caused differing degrees of impairment to pancreatic $\beta$-cell activity, resulting in $\beta$-cell failure $(72,73)$. Lipotoxic effects lead to impaired insulin secretion and apoptosis of $\beta$-cells, which can give rise to the $\beta$-cell functional loss in the pathogenesis of T2DM (74). In the downregulated group, more corresponding encoded proteins were distributed in the plasma membrane and nucleus layers, and BPs were related to the 'positive regulation of cell death' and 'positive regulation of cell proliferation'. Previous studies demonstrated that glucotoxic conditions are used to elevate $\beta$-cell proliferation and neogenesis, and the inhibition of apoptosis and death lead to insulin release defects, which is typical of diabetes $(75,76)$; $\beta$-cell death is the major cause of T2DM. According to protein subcellular localization, the composition and biological value of proteins could change; analyzing PPIs may help identify the signaling pathways. The 
A
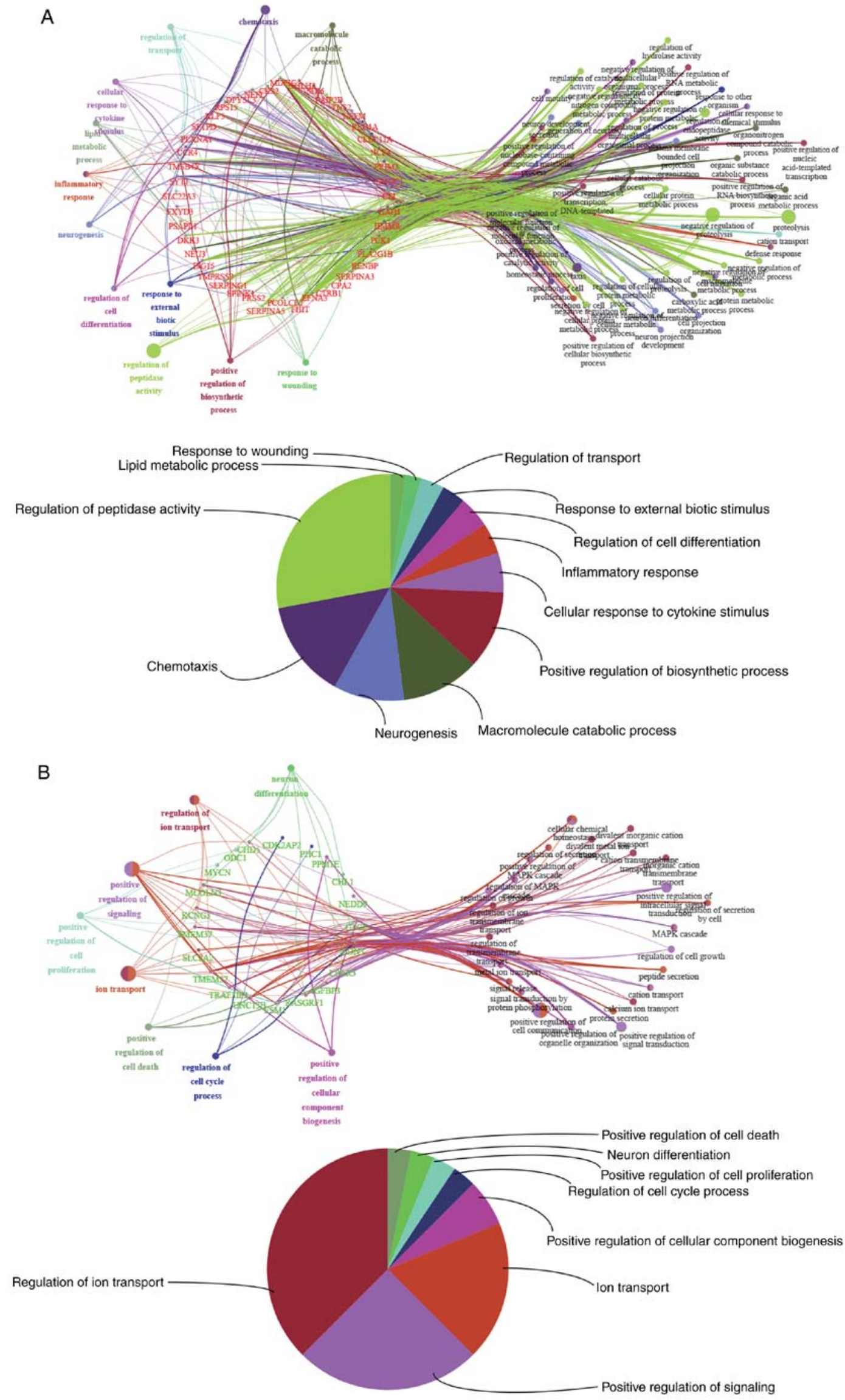

Figure 4. Enriched GO network groups. (A) BP-enrichment analysis using ClueGO and CluePedia for upregulated genes (red). (B) BP-enrichment analysis using ClueGO and CluePedia for downregulated genes (green). Each node is a BP. Edges are links between the nodes and the length of edge indicates the degree of relatedness of two processes. The most significant parent or child term per group is displayed in the ClueGO grouped network as a group title. The size of the nodes indicates enrichment significance of the GO terms. Node color indicates the class. Mixed colors indicate that the particular node is owned by multiple classes. GO, Gene Ontology; BP, biological process. 

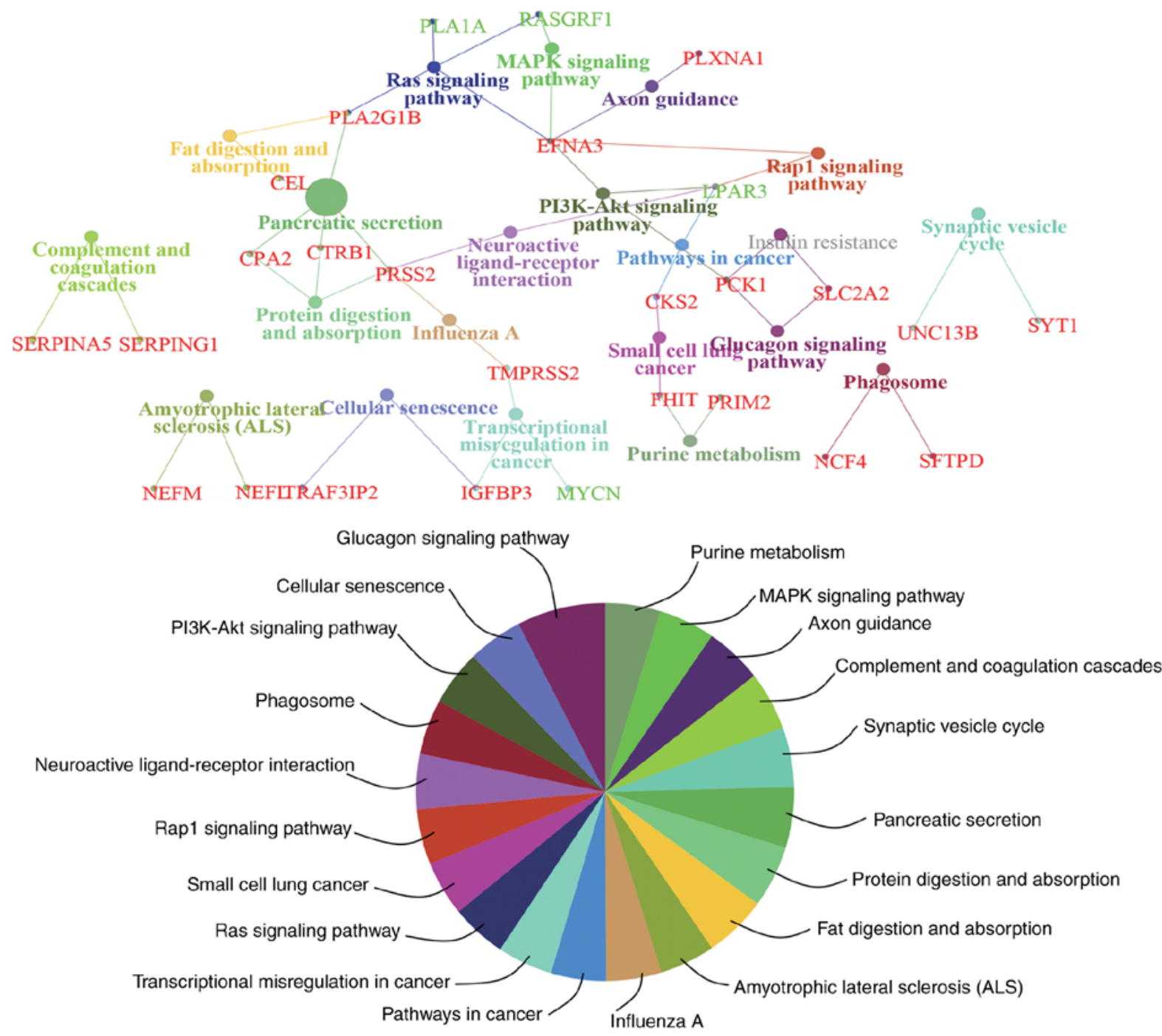

Figure 5. Group of significant Kyoto Encyclopedia of Genes and Genomes pathways of differentially expressed genes. Each node is a main pathway and their relation to genes (red is upregulated and green is downregulated). The node size indicates the significance of the pathway and the edge between nodes indicates shared or common genes. Dissimilar colors of node indicate dissimilar functional groups. The most significant pathway of each group is highlighted in different colors.

present study identified three interactions among 83 candidate genes, including SERPINA3 and CTRB1 in the extracellular matrix, SERPING1 and thymosin b4 X-linked (TMSB4X) in the cytoplasm, and $S Y T 1$ and $U N C 13 B$ in the cytoplasm, which were shared between BPs, including protein input into the cytoplasm and cell-cell signaling, which might indicate that their expression was altered by the signaling cascades of the extracellular-plasma membrane-cytoplasm or nucleus and alteration in cell development. Takahashi et al (77) identified that SERPINA3 levels were significantly increased in T2DM. The rs 7202877 locus for CTRB1 and CTRB2, a known diabetes risk locus, might be able to prevent diabetes via the incretin pathway (78). SERPINA5 inhibits activated protein C (APC). APC has a potential preventative role for islet $\beta$-cell damage and diabetes (79). A previous study observed that the plasma levels of $A P C$ were notably decreased in T2DM (80). SERPINA5 may be involved in T2DM via inhibited APC expression. TMSB $4 X$ is involved in cell proliferation, migration and differentiation, and its level increased in diabetic membranes (81).
The enriched KEGG pathways of candidate genes involved 'MAPK signaling pathway', 'Ras signaling pathway', 'PI3K-Akt signaling pathway', 'Rap1 signaling pathway' and 'purine metabolism'. Previous studies demonstrated that $\mathrm{p} 38$ MAPK and ERK signaling were activated to inhibit obesity and associated T2DM $(82,83)$. The Ras/Raf/ERK signaling pathway may control $\beta$-cell proliferation, and Ras is essential for normal $\beta$-cell development and function (84). Saltiel and Kahn (75) demonstrated that any obstacles in the PI3K/Akt insulin signaling pathway result in islet $\beta$-cells insulin resistance and lead to $\beta$-cell function reduction. Previous studies demonstrated that the Rapl pathway may yield targets for $\beta$-cell dysfunction therapy in diabetes (85-88). The pathway enrichment results for candidate genes in the present study identified the MAPK. Ras, PI3K-Akt and Rap1 signaling pathways in diabetes. RASGRF1 is mainly involved in the MAPK and Ras signaling pathways (89). Suppressing the expression of Rasgrf1 may contribute to insufficient insulin secretion (90), which due to insulin resistance, causes T2DM. In addition, EFNA3 in the extracellular matrix was enriched in the PI3K-Akt, MAPK, 


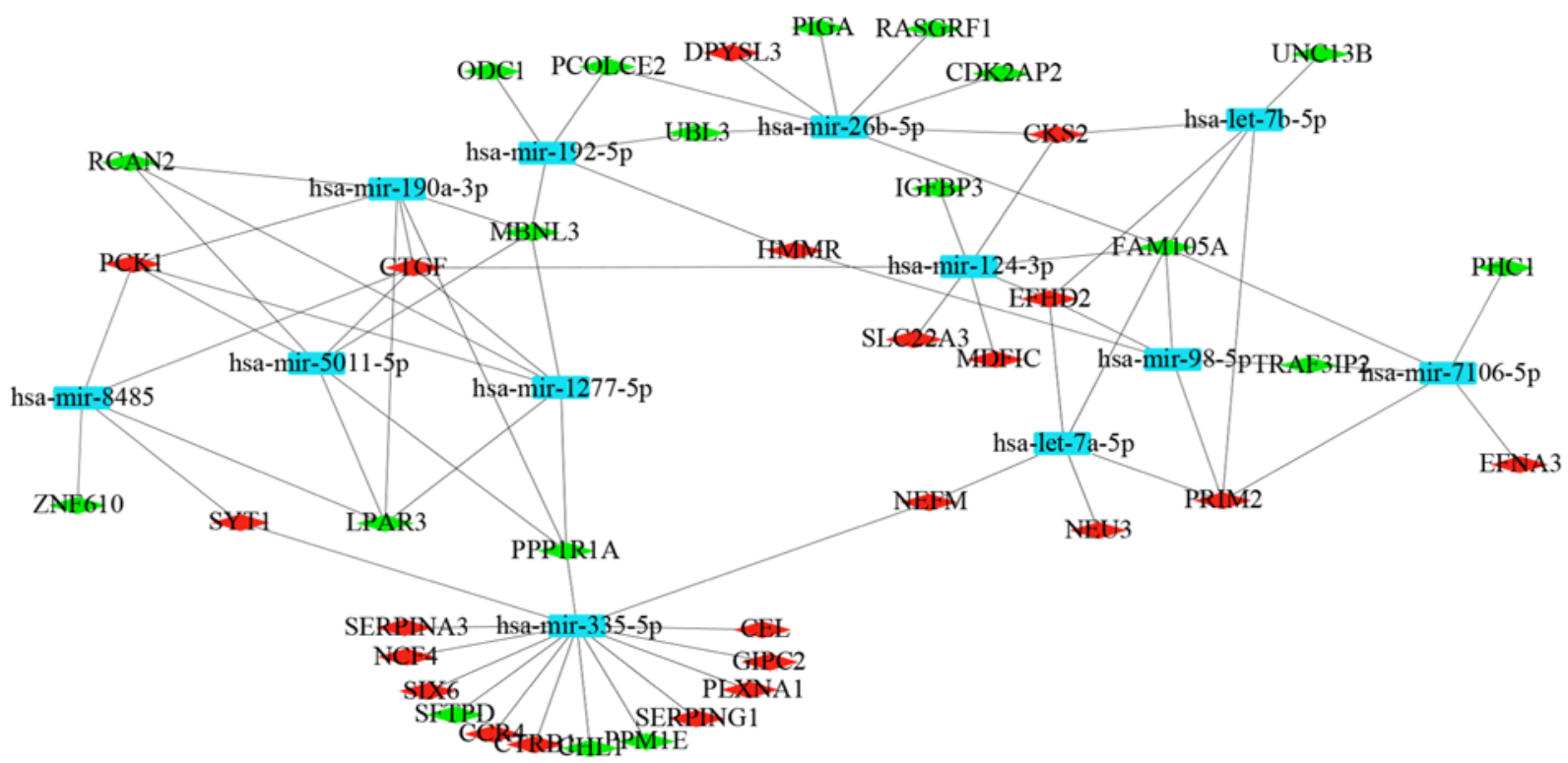

Figure 6. miRNA-target gene regulatory networks. The red diamonds indicate upregulated genes, the green diamonds indicate downregulated genes and the blue squares indicate miRNAs. miRNA/miR, microRNA.

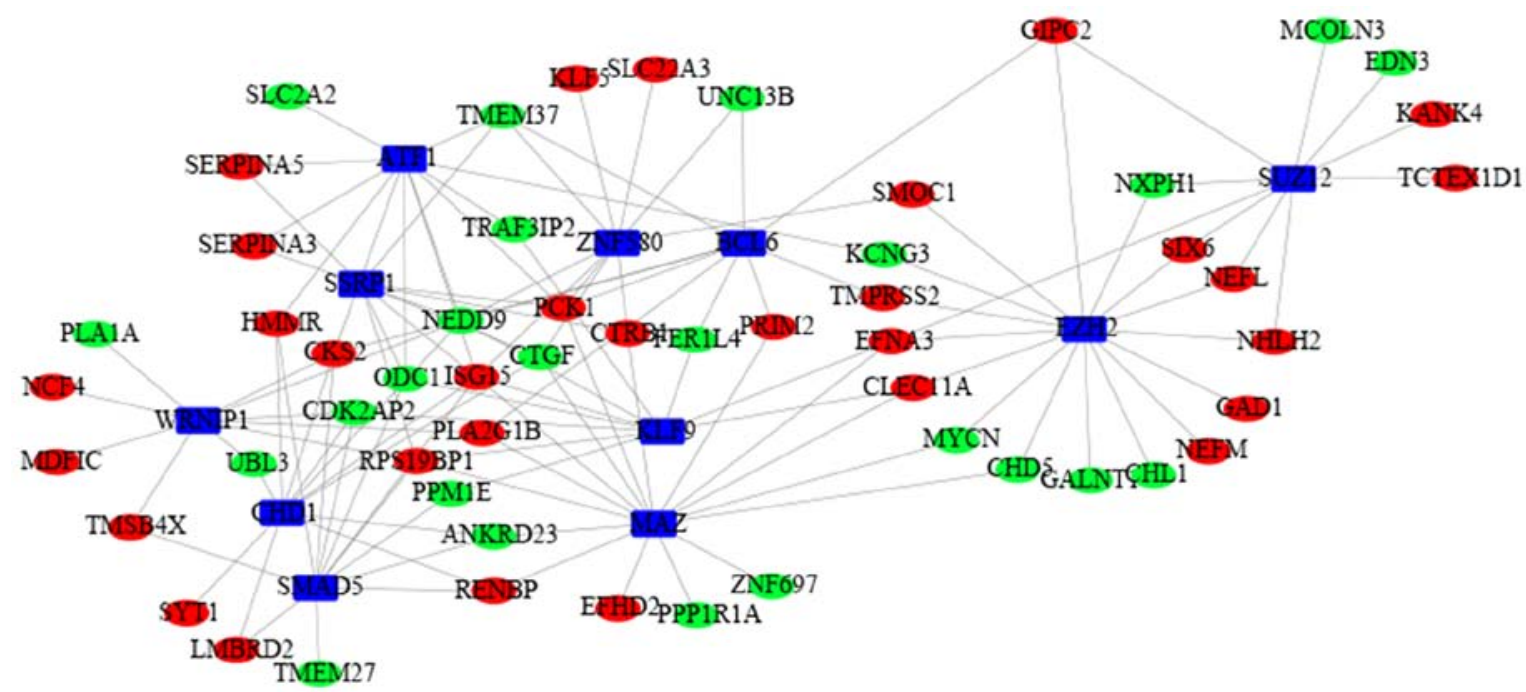

Figure 7. TF-target gene regulatory network. Red indicates upregulated genes, green indicates downregulated genes and blue indicates TFs. TF, transcription factor.

Rap1 and Ras signaling pathways. EFNA3 is an upstream gene of the MAPK signaling pathway and the PI3K-Akt signaling pathway (91). Therefore, it was hypothesized that a low expression of EFNA3 may regulate $\beta$-cell proliferation by activating Ras/Raf/MEK/ERK. FHIT, a protein product involved in purine metabolism that participates in the T2DM pathway, is expressed in the pancreas (92). Its single-nucleotide polymorphism (rs3845971) was related to an intensified risk of T2DM (93). FHIT increases adenosine-diphosphate in the purine metabolism pathway (94). Therefore, FHIT may induce $\beta$-cell apoptosis in the pancreas due to T2DM.

miRNA-target gene interaction networks were constructed from 12 miRNAs. HMMR, ubiquitin like 3, ornithine decarboxylase 1, muscleblind like splicing regulator 3 and procollagen C-endopeptidase enhancer 2 (PCOLCE2) were regulated by hsa-miR-192-5p. Connective tissue growth factor $(C T G F)$, family with sequence similarity 105 , member A (FAM105A), MyoD family inhibitor domain containing, soluble carrier family 22 member 3, IGFBP3, CKS 2 and EF-hand domain family member D2 were regulated by hsa-miR-124-3p. Protein phosphatase 1 regulatory inhibitor subunit 1 A (PPPIRIA), C-C motif chemokine receptor 4 (CCR4), SYT1, LMBR1 domain containing 2,C-type lectin domain containing 11A, NLR family pyrin domain containing 13, SERPINA3, protein phosphatase, $\mathrm{Mg} 2+/ \mathrm{Mn} 2+$ dependent 1E (PPMIE), GIPC PDZ domain containing family member $2, N C F 4$, SERPING1, SIX homebox 6 CTRB1, CEL, cell adhesion molecular L1 like (CHL1), SFTPD and PLXNAI were regulated by hsa-miR-335-5p. It was observed that hsa-miR-192-5p, hsa-miR-124-3p and hsa-miR-335-5p appeared to regulate the majority of the candidate genes identified in T2DM in the present study. It was previously identified that the downregulation of miR-192-5p 
usually occurs in the more extreme stages of diabetes (95). $P C O L C E 2$, a collagen-related gene, is significantly reduced in T2DM (96). Zhu et al (97), identified that the expression level of hsa-miR-124-3p is decreased in patients with T2DM [9 high-body mass index (BMI) and 1 low-BMI] CTGF expression, a vital adjudicator of progressive pancreatic fibrosis, is elevated in T2DM (98). FAM105A is reported to be associated with T2DM (36). miR-335-5p expression was increased by islets in a diabetic Goto-Kakizaki-rat model (99). PPPIRIA has previously been identified as a potential participant and experimentally validated in the pathogenesis of islet dysfunction in T2DM (100). The ratio of $C X C R 3$ to CCR4 receptor expression was positively correlated with the duration of T1D $(r=0.947$; $\mathrm{P}=0.0004)$ (101). The expression of SERPINA3 was increased significantly in T2DM and can be used for the early detection of T2DM (77). PPMIE is a potential drug target for diabetic therapies (102). The CTRB1/2 locus influences the susceptibility and treatment for diabetes via the incretin pathway (78). It was previously identified that mutations for the highly polymorphic CEL gene can be a rare cause of monogenic diabetes (103). CHL1 affects insulin secretion in INS-1 cells and has been identified as being potentially involved in T2DM (104). SFTPD expression was decreased in patients with T2DM (65). Therefore, has-miR-8485, has-miR-1277-3p, has-miR-190a-3p, has-miR-5011-3p, has-let-7a-5p, has-let-7b-5p, has-miR-98-5p, has-miR-7106-5p and has-miR-26b-5p may also be involved in T2DM by potentially regulating the expression of various candidate genes, such as CTGF, PCK1, PPPIRA, PCOLCE2, FAM105A, TRAF3PI2 and neuraminidase 3.

A TF-target gene regulatory network was constructed, from which $10 \mathrm{TFs}$ were identified and Smad5 was a potential target for T2DM treatment (105). The Forkhead box class $\mathrm{O} / \mathrm{Bcl6} /$ cyclin D2 pathway connects nutrient and growth factor status to cell cycle control in pancreatic $\beta$-cells, and should therefore be considered for its therapeutic potential in diabetes (106). Notably, 8 of these transcription regulatory factors, SUZ12, EZH2, ZNF580, KLF9, MAZ, ATF1, SSRP1, WRNIP1, CHD1 were shown to be involved in the development of T2DM by modulating the expression of various candidate genes such as ankyrin repeat domain 23 (ANKRD23), transmembrane protein 37 (TMEM37), PPPIR1A, PCK1, CTGF, $I S G 1, S S R P I, W R N I P I$ and CHDI, which have not been previously reported to be dysregulated in T2DM. The present study predicted that these TFs might play key roles in the occurrence and development of T2DM. This result provided preliminary evidence that a lower expression of TMEM37 could reflect a decrease in $\beta$-cell numbers in T2DM (107). ANKRD23, a diabetes-related ankyrin repeat protein, was identified as a novel gene that is upregulated in the hearts of KKA(y) mice, a T2DM and insulin-resistant animal model (108). Solimena et al (110) also identified that ANKRD23, PPPIRIA and TMEM37 were enriched in $\beta$-cells and downregulated in T2DM. TMEM37 prohibits $\mathrm{Ca}^{2+}$-influx and insulin secretion in $\beta$-cells (109).

The present study has some limitations. The number of samples was relatively inadequate, although the combining of multiple datasets can compensate for missing or unreliable information in any single dataset. Additionally, the present results are preliminary and descriptive. Integrative analysis of gene profiling data cannot entirely exclude false positive results. Furthermore, the present study only discussed mRNA expression and did not refer to the protein expression of the factors identified. Due to post-transcription regulatory events, protein expression levels may or may not correlate with mRNA levels. However, the alteration of protein structure, function and interaction is the underlying mechanism of a number of diseases, including diabetes (110-112). Therefore, some experiments, such as reverse transcription-quantitative PCR $(113,114)$, western blotting (115), cross-linking immunoprecipitation (116) or functional experimental validation, are needed to validate key genes, TFs and miRNAs and relevant proteins in T2DM development. Despite these limitations, the present study still provided insight for understanding the complicated underlying molecular mechanisms of T2DM.

Overall, the bioinformatics analysis of the present study identified potential markers that may play a potential role in the occurrence, development and treatment of T2DM. A total of 83 candidate genes were selected, and ISG15,PCKI,SYTI,IGFBP3, TIMM44 and TRAF3IP2 could be the core genes of T2DM. Certain key BPs such as 'inflammatory response', 'cellular responses to cytokine stimulus', 'lipid metabolic process', 'positive regulation of cell death' and 'positive regulation of cell proliferation', and certain signaling pathways associated with the PI3K-Akt, MAPK, Rap1 and Ras signaling pathways were identified to be involved in T2DM. The present study also identified miRNAs, including hsa-miR-192-5p, hsa-miR-124-5p and hsa-miR-335-5p, and TFs, including Smad5 and Bcl6, that might be potential targets for the diagnosis and treatment of T2DM. In addition, has-miR-8485, has-miR-1277-3p, has-miR-190a-3p, has-miR-5011-3p, has-let-7a-5p, has-let-7b-5p, has-miR-98-5p, has-miR-7106-5p and has-miR-26b-5p, and TFs SUZ12, EZH2, ZNF580, KLF9, MAZ, ATF1, SSRP1, WRNIP1 and CHD1 have not been previously identified to be related to T2DM, to the best of the authors' knowledge, while they and their target genes may serve as diagnostic indicators for patients with T2DM. To obtain more reliable correlation results, it is necessary to validate the predicted results with a series of verification experiments. The present study identified candidate genes for T2DM development, which might be redefined as pathogenic genes for T2DM diagnosis and therapy. The experimental results could provide insight for future genomic individualized treatment of T2DM and help to identify the underlying molecular mechanisms that lead to T2DM.

\section{Acknowledgements}

Not applicable.

\section{Funding}

The present study was supported by The National Natural Science Foundation of China (grant no. c010201), Startup Funding for Specialized Professorship provided by The Shanghai Jiao Tong University (grant no. WF220441502), The National Key Research and Development Program (grant no. 2017YFC1308605), The Fundamental Research Funds for The Central Universities Key Grant (grant no. CQDXWL-2014-Z002), a grant (grant no. YZYN-15-04) from The Basic Scientific Research Special of The Central Public Welfare Research Institutes of Medicinal Plant Development, Chinese Academy of Medical Sciences 
and Peking Union Medical College, The Applied Basic Research Foundation of Yunnan Province of China (grant no. 2016FB143), The National Natural Science Foundation of China (grant no. 81503289) and The PUMC Youth Fund (grant no. 2017350013).

\section{Availability of data and materials}

The datasets used or analyzed during the present study are included in this article.

\section{Authors' contributions}

HL and GL designed and conceived the experiments. YLu, GL and YLi collected and analyzed the data. HL and YL wrote the manuscript, and all authors reviewed the manuscript.

\section{Ethics approval and consent to participate}

Not applicable.

\section{Patient consent for publication}

Not applicable.

\section{Competing interests}

The authors declare that they have no competing interests.

\section{References}

1. Zheng Y, Ley SH and Hu FB: Global aetiology and epidemiology of type 2 diabetes mellitus and its complications. Nat Rev Endocrinol 14: 88-98, 2018.

2. International Diabetes Federation: IDF Diabetes Atlas. 8th edition. IDF, Brussels, Belgium, 2017. http://www.diabetesatlas.org.

3. Ohn JH, Kwak SH, Cho YM, Lim S, Jang HC, Park KS and Cho NH: 10 -year trajectory of $\beta$-cell function and insulin sensitivity in the development of type 2 diabetes: A community-based prospective cohort study. Lancet Diabetes Endocrinol 4: 27-34, 2016.

4. Ashcroft FM, Rohm M, Clark A and Brereton MF: Is type 2 diabetes a glycogen storage disease of pancreatic $\beta$ cells? Cell Metab 26: 17-23, 2017.

5. Almaça J, Weitz J, Rodriguez-Diaz R, Pereira E and Caicedo A: The pericyte of the pancreatic islet regulates capillary diameter and local blood flow. Cell Metab 27: 630-644.e4, 2018.

6. Wei FJ, Cai CY, Yu P, Lv J, Ling C, Shi WT, Jiao HX, Chang BC, Yang FH, Tian Y, et al: Quantitative candidate gene association studies of metabolic traits in Han Chinese type 2 diabetes patients. Genet Mol Res 14: 15471-15481, 2015.

7. Chen J, Meng Y, Zhou J, Zhuo M, Ling F, Zhang Y, Du H and Wang X: Identifying candidate genes for type 2 diabetes mellitus and obesity through gene expression profiling in multiple tissues or cells. J Diabetes Res 2013: 970435, 2013.

8. Lynch CJ and Adams SH: Branched-chain amino acids in metabolic signalling and insulin resistance. Nat Rev Endocrinol 10: 723-736, 2014.

9. Xue A, Wu Y, Zhu Z, Zhang F, Kemper KE, Zheng Z, Yengo L, Lloyd-Jones LR, Sidorenko J, Wu Y, et al: eQTLGen Consortium: Genome-wide association analyses identify 143 risk variants and putative regulatory mechanisms for type 2 diabetes. Nat Commun 9: 2941, 2018.

10. Lawlor N, Khetan S, Ucar D and Stitzel ML: Genomics of Islet (Dys)function and Type 2 Diabetes. Trends Genet 33: 244-255, 2017.

11. Lee I, Blom UM, Wang PI, Shim JE and Marcotte EM: Prioritizing candidate disease genes by network-based boosting of genome-wide association data. Genome Res 21: 1109-1121, 2011.
12. Lawlor N, George J, Bolisetty M, Kursawe R, Sun L, Sivakamasundari V, Kycia I, Robson P and Stitzel ML: Single-cell transcriptomes identify human islet cell signatures and reveal cell-type-specific expression changes in type 2 diabetes. Genome Res 27: 208-222, 2017.

13. Segerstolpe A, Palasantza A, Eliasson P, Andersson EM, Andréasson AC, Sun X, Picelli S, Sabirsh A, Clausen M, Bjursell MK, et al: Single-cell transcriptome profiling of human pancreatic islets in health and type 2 diabetes. Cell Metab 24: 593-607, 2016.

14. Zeggini E, Scott LJ, Saxena R, Voight BF, Marchini JL, Hu T, de Bakker PI, Abecasis GR, Almgren P, Andersen G, et al; Wellcome Trust Case Control Consortium: Meta-analysis of genome-wide association data and large-scale replication identifies additional susceptibility loci for type 2 diabetes. Nat Genet 40: 638-645, 2008.

15. Maruthur NM, Gribble MO, Bennett WL, Bolen S, Wilson LM, Balakrishnan P, Sahu A, Bass E, Kao WH and Clark JM: The pharmacogenetics of type 2 diabetes: A systematic review. Diabetes Care 37: 876-886, 2014.

16. van de Bunt M, Manning Fox JE, Dai X, Barrett A, Grey C, Li L, Bennett AJ, Johnson PR, Rajotte RV, Gaulton KJ, et al: Transcript expression data from human islets links regulatory signals from genome-wide association studies for type 2 diabetes and glycemic traits to their downstream effectors. PLoS Genet 11: e1005694, 2015.

17. Bonnefond A and Froguel P: Rare and common genetic events in type 2 diabetes: What should biologists know? Cell Metab 21: 357-368, 2015.

18. Ndiaye FK, Ortalli A, Canouil M, Huyvaert M, Salazar-Cardozo C, Lecoeur C, Verbanck M, Pawlowski V, Boutry R, Durand E, et al: Expression and functional assessment of candidate type 2 diabetes susceptibility genes identify four new genes contributing to human insulin secretion. Mol Metab 6: 459-470, 2017.

19. Pellegrino M, Sciambi A, Treusch S, Durruthy-Durruthy R, Gokhale K, Jacob J, Chen TX, Geis JA, Oldham W, Matthews J, et al: High-throughput single-cell DNA sequencing of acute myeloid leukemia tumors with droplet microfluidics. Genome Res 28: 1345-1352, 2018.

20. Zhang P, Xia JH, Zhu J, Gao P, Tian YJ, Du M, Guo YC, Suleman S, Zhang Q, Kohli M, et al: High-throughput screening of prostate cancer risk loci by single nucleotide polymorphisms sequencing. Nat Commun 9: 2022, 2018.

21. Nepal C, O'Rourke CJ, Oliveira DVNP, Taranta A, Shema S, Gautam P, Calderaro J, Barbour A, Raggi C, Wennerberg K, et al: Genomic perturbations reveal distinct regulatory networks in intrahepatic cholangiocarcinoma. Hepatology 68: 949-963, 2018.

22. Fuchsberger C, Flannick J, Teslovich TM, Mahajan A, Agarwala V, Gaulton KJ, Ma C, Fontanillas P, Moutsianas L, McCarthy DJ, et al: The genetic architecture of type 2 diabetes. Nature 536: 41-47, 2016

23. Thul PJ, Åkesson L, Wiking M, Mahdessian D, Geladaki A, Ait Blal H, Alm T, Asplund A, Björk L, Breckels LM, et al: A subcellular map of the human proteome. Science 356: 806, 2017.

24. Zhu H, Bilgin M and Snyder M: Proteomics. Annu Rev Biochem 72: 783-812, 2003.

25. Larance M and Lamond AI: Multidimensional proteomics for cell biology. Nat Rev Mol Cell Biol 16: 269-280, 2015.

26. Stuart LM, Boulais J, Charriere GM, Hennessy EJ, Brunet S, Jutras I, Goyette G, Rondeau C, Letarte S, Huang H, et al: A systems biology analysis of the Drosophila phagosome. Nature 445: 95-101, 2007.

27. Zhao L, Chen Y, Bajaj AO, Eblimit A, Xu M, Soens ZT, Wang F, Ge Z, Jung SY, He F, et al: Integrative subcellular proteomic analysis allows accurate prediction of human disease-causing genes. Genome Res 26: 660-669, 2016.

28. Hunt KK, Karakas C, Ha MJ, Biernacka A, Yi M, Sahin AA, Adjapong O, Hortobagyi GN, Bondy M, Thompson P, et al: Cytoplasmic Cyclin E Predicts Recurrence in Patients with Breast Cancer. Clin Cancer Res 23: 2991-3002, 2017.

29. Mezzanzanica D, Fabbi M, Bagnoli M, Staurengo S, Losa M, Balladore E, Alberti P, Lusa L, Ditto A,Ferrini S, et al: Subcellular localization of activated leukocyte cell adhesion molecule is a molecular predictor of survival in ovarian carcinoma patients. Clin Cancer Res 14: 1726-1733, 2008.

30. Zhu W, Yang L and Du Z: Layered functional network analysis of gene expression in human heart failure. PLoS One 4: e6288, 2009. 
31. Du ZP, Wu BL, Wang SH, Shen JH, Lin XH, Zheng CP, Wu ZY, Qiu XY, Zhan XF, Xu LY, et al: Shortest path analyses in the protein-protein interaction network of NGAL (neutrophil gelatinase-associated lipocalin) overexpression in esophageal squamous cell carcinoma. Asian Pac J Cancer Prev 15: 6899-6904, 2014.

32. Diao B, Liu Y, Zhang Y, Liu Q, Lu WJ and Xu G: Functional network analysis with the subcellular location and gene ontology information in human allergic asthma. Genet Test Mol Biomarkers 16: 1287-1292, 2012.

33. Lee S, Zhang C, Kilicarslan M, Piening BD, Bjornson E, Hallström BM, Groen AK, Ferrannini E, Laakso M, Snyder M, et al: Integrated Network Analysis Reveals an Association between Plasma Mannose Levels and Insulin Resistance. Cell Metab 24: 172-184, 2016.

34. Alvarez MJ, Shen Y, Giorgi FM, Lachmann A, Ding BB, Ye BH and Califano A: Functional characterization of somatic mutations in cancer using network-based inference of protein activity. Nat Genet 48: 838-847, 2016.

35. Krell J, Stebbing J, Frampton AE, Carissimi C, Harding V, De Giorgio A, Fulci V, Macino G, Colombo T and Castellano L: The role of TP53 in miRNA loading onto AGO2 and in remodelling the miRNA-mRNA interaction network. Lancet 385 (Suppl 1): S15, 2015.

36. Marselli L, Thorne J, Dahiya S, Sgroi DC, Sharma A, Bonner-Weir S, Marchetti P and Weir GC: Gene expression profiles of Beta-cell enriched tissue obtained by laser capture microdissection from subjects with type 2 diabetes. PLoS One 5 : e11499, 2010

37. Keshava Prasad TS, Goel R, Kandasamy K, Keerthikumar S, Kumar S, Mathivanan S, Telikicherla D, Raju R, Shafreen B, Venugopal A, et al: Human Protein Reference Database--2009 update. Nucleic Acids Res 37 (Database): D767-D772, 2009.

38. Chatr-Aryamontri A, Breitkreutz BJ, Oughtred R, Boucher L, Heinicke S, Chen D, Stark C, Breitkreutz A, Kolas N, O'Donnell L, et al: The BioGRID interaction database: 2015 update. Nucleic Acids Res 43 (D1): D470-D478, 2015.

39. Kerrien S, Aranda B, Breuza L, Bridge A, Broackes-Carter F, Chen C, Duesbury M, Dumousseau M, Feuermann M, Hinz U, et al: The IntAct molecular interaction database in 2012 . Nucleic Acids Res 40 (D1): D841-D846, 2012.

40. Szklarczyk D, Franceschini A, Wyder S, Forslund K, Heller D, Huerta-Cepas J, Simonovic M, Roth A, Santos A, Tsafou KP, et al: STRING v10: Protein-protein interaction networks, integrated over the tree of life. Nucleic Acids Res 43 (D1): D447-D452, 2015.

41. Shannon P, Markiel A, Ozier O, Baliga NS, Wang JT, Ramage D, Amin N, Schwikowski B and Ideker T: Cytoscape: A software environment for integrated models of biomolecular interaction networks. Genome Res 13: 2498-2504, 2003.

42. Pontén F, Jirström K and Uhlen M: The Human Protein Atlas--a tool for pathology. J Pathol 216: 387-393, 2008.

43. Barsky A, Gardy JL, Hancock RE and Munzner T: Cerebral: A Cytoscape plugin for layout of and interaction with biological networks using subcellular localization annotation. Bioinformatics 23: 1040-1042, 2007.

44. Bindea G, Galon J and Mlecnik B: CluePedia Cytoscape plugin: Pathway insights using integrated experimental and in silico data. Bioinformatics 29: 661-663, 2013.

45. Bindea G, Mlecnik B, Hackl H, Charoentong P, Tosolini M, Kirilovsky A, Fridman WH, Pagès F, Trajanoski Z and Galon J: ClueGO: A Cytoscape plug-in to decipher functionally grouped gene ontology and pathway annotation networks. Bioinformatics 25: 1091-1093, 2009.

46. Gene Ontology Consortium: Gene Ontology Consortium: Going forward. Nucleic Acids Res 43 (D1): D1049-D1056, 2015.

47. Kanehisa M, Furumichi M, Tanabe M, Sato Y and Morishima K KEGG: New perspectives on genomes, pathways, diseases and drugs. Nucleic Acids Res 45 (D1): D353-D361, 2017.

48. Fan Y, Siklenka K, Arora SK, Ribeiro P, Kimmins S and Xia J: miRNet - dissecting miRNA-target interactions and functional associations through network-based visual analysis. Nucleic Acids Res 44 (W1): W135-41, 2016.

49. Chou CH, Chang NW, Shrestha S, Hsu SD, Lin YL, Lee WH, Yang CD, Hong HC, Wei TY, Tu SJ, et al: miRTarBase 2016 Updates to the experimentally validated miRNA-target interactions database. Nucleic Acids Res 44 (D1): D239-D247, 2016.

50. Xiao F, Zuo Z, Cai G, Kang S, Gao X and Li T: miRecords: An integrated resource for microRNA-target interactions. Nucleic Acids Res 37 (Database): D105-D110, 2009.
51. Xia J, Gill EE and Hancock RE: NetworkAnalyst for statistical, visual and network-based meta-analysis of gene expression data. Nat Protoc 10: 823-844, 2015.

52. Wang S, Sun H, Ma J, Zang C, Wang C, Wang J, Tang Q, Meyer CA, Zhang Y and Liu XS: Target analysis by integration of transcriptome and ChIP-seq data with BETA. Nat Protoc 8: 2502-2515, 2013

53. Yoshikawa A, Imagawa A, Nakata S, Fukui K, Kuroda Y, Miyata Y, Sato Y, Hanafusa T, Matsuoka TA, Kaneto H, et al: Interferon stimulated gene 15 has an anti-apoptotic effect on MIN6 cells. Endocr J 61: 883-890, 2014.

54. Rees SD, Britten AC, Bellary S, O'Hare JP, Kumar S, Barnett AH and Kelly MA: The promoter polymorphism $-232 \mathrm{C} / \mathrm{G}$ of the PCK1 gene is associated with type 2 diabetes in a UK-resident South Asian population. BMC Med Genet 10: 83, 2009.

55. Gustavsson $\mathrm{N}$ and Han W: Calcium-sensing beyond neurotransmitters: Functions of synaptotagmins in neuroendocrine and endocrine secretion. Biosci Rep 29: 245-259, 2009.

56. Marshall C, Hitman GA, Partridge CJ, Clark A, Ma H, Shearer TR and Turner MD: Evidence that an isoform of calpain-10 is a regulator of exocytosis in pancreatic beta-cells. Mol Endocrinol 19: 213-224, 2005.

57. Rajpathak SN, He M, Sun Q, Kaplan RC, Muzumdar R, Rohan TE, Gunter MJ, Pollak M, Kim M, Pessin JE, et al: Insulin-like growth factor axis and risk of type 2 diabetes in women. Diabetes 61: 2248-2254, 2012.

58. Drogan D, Schulze MB, Boeing H and Pischon T: Insulin-like growth factor 1 and insulin-like growth factor-binding protein 3 in relation to the risk of type 2 diabetes mellitus: Results from the EPIC-Potsdam study. Am J Epidemiol 183: 553-560, 2016.

59. Wang Y, Katayama A, Terami T, Han X, Nunoue T, Zhang D, Teshigawara S, Eguchi J, Nakatsuka A, Murakami K, et al: Translocase of inner mitochondrial membrane 44 alters the mitochondrial fusion and fission dynamics and protects from type 2 diabetes. Metabolism 64: 677-688, 2015.

60. Venkatesan B, Valente AJ, Das NA, Carpenter AJ, Yoshida T, Delafontaine JL, Siebenlist U and Chandrasekar B: CIKS (Actl or TRAF3IP2) mediates high glucose-induced endothelial dysfunction. Cell Signal 25: 359-371, 2013.

61. Bergholdt R, Brorsson C, Palleja A, Berchtold LA, Fløyel T, Bang-Berthelsen CH, Frederiksen KS, Jensen LJ, Størling J and Pociot F: Identification of novel type 1 diabetes candidate genes by integrating genome-wide association data, protein-protein interactions, and human pancreatic islet gene expression. Diabetes 61: 954-962, 2012.

62. Kokkola T, Suuronen T, Molnár F, Määttä J, Salminen A, Jarho EM and Lahtela-Kakkonen M: AROS has a context-dependent effect on SIRT1. FEBS Lett 588: 1523-1528, 2014.

63. Haigis MC and Sinclair DA: Mammalian sirtuins: Biological insights and disease relevance. Annu Rev Pathol 5: 253-295, 2010.

64. Zhou CH, Zhang MX, Zhou SS, Li H, Gao J, Du L and Yin XX: SIRT1 attenuates neuropathic pain by epigenetic regulation of mGluR1/5 expressions in type 2 diabetic rats. Pain 158: 130-139, 2017.

65. Ortega FJ, Pueyo N, Moreno-Navarrete JM, Sabater M, Rodriguez-Hermosa JI, Ricart W, Tinahones FJ and Fernandez-Real JM: The lung innate immune gene surfactant protein-D is expressed in adipose tissue and linked to obesity status. Int J Obes (Lond) (2005) 37: 1532-1538, 2013. https://doi. org/10.1038/ijo.2013.23

66. Crook M: Type 2 diabetes mellitus: A disease of the innate immune system? An update. Diabet Med 21: 203-207, 2004.

67. Yang W, Li Y, Wang JY, Han R and Wang L: Circulating levels of adipose tissue-derived inflammatory factors in elderly diabetes patients with carotid atherosclerosis: A retrospective study. Cardiovasc Diabetol 17: 75, 2018.

68. Prattichizzo F, De Nigris V, Spiga R, Mancuso E, La Sala L, Antonicelli R, Testa R, Procopio AD, Olivieri F and Ceriello A: Inflammageing and metaflammation: The yin and yang of type 2 diabetes. Ageing Res Rev 41: 1-17, 2018.

69. Naidoo V, Naidoo M and Ghai M: Cell- and tissue-specific epigenetic changes associated with chronic inflammation in insulin resistance and type 2 diabetes mellitus. Scand J Immunol 88: e12723, 2018.

70. Ehses JA, Perren A, Eppler E, Ribaux P, Pospisilik JA, Maor-Cahn R, Gueripel X, Ellingsgaard H, Schneider MK, Biollaz G, et al: Increased number of islet-associated macrophages in type 2 diabetes. Diabetes 56: 2356-2370, 2007. 
71. Böni-Schnetzler M, Thorne J, Parnaud G, Marselli L, Ehses JA, Kerr-Conte J, Pattou F, Halban PA, Weir GC and Donath MY: Increased interleukin (IL)-1beta messenger ribonucleic acid expression in beta -cells of individuals with type 2 diabetes and regulation of IL-1beta in human islets by glucose and autostimulation. J Clin Endocrinol Metab 93: 4065-4074, 2008.

72. Donath MY, Böni-Schnetzler M, Ellingsgaard H and Ehses JA: Islet inflammation impairs the pancreatic beta-cell in type 2 diabetes. Physiology (Bethesda) 24: 325-331, 2009.

73. Marchetti P, Lupi R, Del Guerra S, Bugliani M, D'Aleo V, Occhipinti M, Boggi U, Marselli L and Masini M: Goals of treatment for type 2 diabetes: Beta-cell preservation for glycemic control. Diabetes Care 32 (Suppl 2): S178-S183, 2009.

74. Cnop M: Fatty acids and glucolipotoxicity in the pathogenesis of Type 2 diabetes. Biochem Soc Trans 36: 348-352, 2008

75. Saltiel AR and Kahn CR: Insulin signalling and the regulation of glucose and lipid metabolism. Nature 414: 799-806, 2001.

76. Wajchenberg BL: beta-cell failure in diabetes and preservation by clinical treatment. Endocr Rev 28: 187-218, 2007.

77. Takahashi E, Unoki-Kubota H, Shimizu Y, Okamura T, Iwata W, Kajio H, Yamamoto-Honda R, Shiga T, Yamashita S, Tobe K, et al: Proteomic analysis of serum biomarkers for prediabetes using the Long-Evans Agouti rat, a spontaneous animal model of type 2 diabetes mellitus. J Diabetes Investig 8 : 661-671, 2017.

78. Hart LM, Fritsche A, Nijpels G, van Leeuwen N, Donnelly LA, Dekker JM, Alssema M, Fadista J, Carlotti F, Gjesing AP, et al The CTRB1/2 locus affects diabetes susceptibility and treatment via the incretin pathway. Diabetes 62: 3275-3281, 2013.

79. Xue $M$ and Jackson CJ: Activated protein $C$ and its potential applications in prevention of islet $\beta$-cell damage and diabetes. Vitam Horm 95: 323-363, 2014.

80. Matsumoto K, Yano Y, Gabazza EC, Araki R, Bruno NE, Suematsu M, Akatsuka H, Katsuki A, Taguchi O, Adachi Y, et al: Inverse correlation between activated protein $\mathrm{C}$ generation and carotid atherosclerosis in Type 2 diabetic patients. Diabet Med 24: 1322-1328, 2007.

81. Wang JY, Lu Q, Tao Y, Jiang YR and Jonas JB: Intraocular expression of thymosin $\beta 4$ in proliferative diabetic retinopathy. Acta Ophthalmol 89: e396-e403, 2011.

82. Sidarala V and Kowluru A: The regulatory roles of mitogen-activated protein kinase (MAPK) pathways in health and diabetes: Lessons learned from the pancreatic $\beta$-cell. Recent Pat Endocr Metab Immune Drug Discov 10: 76-84, 2017.

83. Pang Y, Zhu H, Xu J, Yang L, Liu L and Li J: $\beta$-arrestin-2 is involved in irisin induced glucose metabolism in type 2 diabetes via p38 MAPK signaling. Exp Cell Res 360: 199-204, 2017.

84. Stewart AF, Hussain MA, García-Ocaña A, Vasavada RC, Bhushan A, Bernal-Mizrachi E and Kulkarni RN: Human $\beta$-cell proliferation and intracellular signaling: Part 3. Diabetes 64 : $1872-1885,2015$

85. Fraenkel M, Ketzinel-Gilad M, Ariav Y, Pappo O, Karaca M, Castel J, Berthault MF, Magnan C, Cerasi E, Kaiser N, et al: mTOR inhibition by rapamycin prevents beta-cell adaptation to hyperglycemia and exacerbates the metabolic state in type 2 diabetes. Diabetes 57: 945-957, 2008.

86. Baeder WL, Sredy J, Sehgal SN, Chang JY and Adams LM: Rapamycin prevents the onset of insulin-dependent diabetes mellitus (IDDM) in NOD mice. Clin Exp Immunol 89: 174-178, 1992.

87. Zhang CL, Katoh M, Shibasaki T, Minami K, Sunaga Y, Takahashi H, Yokoi N, Iwasaki M, Miki T and Seino S: The cAMP sensor Epac2 is a direct target of antidiabetic sulfonylurea drugs. Science 325: 607-610, 2009.

88. Sabbatini ME, Chen X, Ernst SA and Williams JA: Rap1 activation plays a regulatory role in pancreatic amylase secretion. $J$ Biol Chem 283: 23884-23894, 2008.

89. Manyes L,Arribas M,GomezC,CalzadaN,Fernandez-Medarde A and Santos E: Transcriptional profiling reveals functional links between RasGrf1 and Pttg1 in pancreatic beta cells. BMC Genomics 15: 1019, 2014.

90. Hoffmann A and Spengler D: Transient neonatal diabetes mellitus gene Zacl impairs insulin secretion in mice through Rasgrf1. Mol Cell Biol 32: 2549-2560, 2012.

91. Yang Y, Fu Q, Wang X, Liu Y, Zeng Q, Li Y, Gao S, Bao L, Liu S, Gao D, et al: Comparative transcriptome analysis of the swimbladder reveals expression signatures in response to low oxygen stress in channel catfish, Ictalurus punctatus. Physiol Genomics 50: 636-647, 2018 .
92. Dong Q, Ginsberg HN and Erlanger BF: Overexpression of the A1 adenosine receptor in adipose tissue protects mice from obesity-related insulin resistance. Diabetes Obes Metab 3 360-366, 2001

93. Rampersaud E, Damcott CM, Fu M, Shen H, McArdle P, Shi X, Shelton J, Yin J, Chang YP, Ott SH, et al: Identification of novel candidate genes for type 2 diabetes from a genome-wide association scan in the Old Order Amish: Evidence for replication from diabetes-related quantitative traits and from independent populations. Diabetes 56: 3053-3062, 2007.

94. Straub SG and Sharp GW: Glucose-stimulated signaling pathways in biphasic insulin secretion. Diabetes Metab Res Rev 18: 451-463, 2002.

95. Ma X, Lu C, Lv C, Wu C and Wang Q: The expression of miR-192 and its significance in diabetic nephropathy patients with different urine albumin creatinine ratio. J Diabetes Res 2016: 6789402, 2016

96. Wu C, Chen X, Shu J and Lee CT: Whole-genome expression analyses of type 2 diabetes in human skin reveal altered immune function and burden of infection. Oncotarget 8: 34601-34609, 2017.

97. Zhu Z, Yin J, Li DC and Mao ZQ: Role of microRNAs in the treatment of type 2 diabetes mellitus with Roux-en-Y gastric bypass. Braz J Med Biol Res 50: e5817, 2017.

98. Pivovarova O, Fisher E, Dudziak K, Ilkavets I, Dooley S, Slominsky P, Limborska S, Weickert MO, Spranger J, Fritsche A, et al: A polymorphism within the connective tissue growth factor (CTGF) gene has no effect on non-invasive markers of beta-cell area and risk of type 2 diabetes. Dis Markers 31: 241-246, 2011.

99. Salunkhe VA, Ofori JK, Gandasi NR, Salo SA, Hansson S Andersson ME, Wendt A, Barg S, Esguerra JLS and Eliasson L: MiR-335 overexpression impairs insulin secretion through defective priming of insulin vesicles. Physiol Rep 52017. https://doi.org/10.14814/phy2.13493.

100. Taneera J, Fadista J, Ahlqvist E, Atac D, Ottosson-Laakso E, Wollheim CB and Groop L: Identification of novel genes for glucose metabolism based upon expression pattern in human islets and effect on insulin secretion and glycemia. Hum Mol Genet 24: 1945-1955, 2015

101. Aso Y, Matsuura H, Momobayashi A, Inukai Y, Sugawara N, Nakano T, Yamamoto R, Wakabayashi S, Takebayashi K and Inukai T: Profound reduction in T-helper (Th) 1 lymphocytes in peripheral blood from patients with concurrent type 1 diabetes and Graves' disease. Endocr J 53: 377-385, 2006.

102. Voss M, Paterson J, Kelsall IR, Martín-Granados C, Hastie CJ, Peggie MW and Cohen PT: Ppm1E is an in cellulo AMP-activated protein kinase phosphatase. Cell Signal 23: 114-124, 2011.

103. Torsvik J, Johansson S, Johansen A, Ek J, Minton J, Raeder H, Ellard S, Hattersley A, Pedersen O, Hansen T, et al: Mutations in the VNTR of the carboxyl-ester lipase gene (CEL) are a rare cause of monogenic diabetes. Hum Genet 127: 55-64, 2010.

104. Taneera J, Lang S, Sharma A, Fadista J, Zhou Y, Ahlqvist E, Jonsson A, Lyssenko V, Vikman P, Hansson O, et al: A systems genetics approach identifies genes and pathways for type 2 diabetes in human islets. Cell Metab 16: 122-134, 2012

105. Anhê FF, Lellis-Santos C, Leite AR, Hirabara SM, Boschero AC, Curi R, Anhê GF and Bordin S: Smad5 regulates Akt2 expression and insulin-induced glucose uptake in L6 myotubes. Mol Cell Endocrinol 319: 30-38, 2010.

106. Glauser DA and Schlegel W: The FoxO/Bcl-6/cyclin D2 pathway mediates metabolic and growth factor stimulation of proliferation in Min6 pancreatic beta-cells. J Recept Signal Transduct Res 29: 293-298, 2009.

107. Rechsteiner MP, Floros X, Boehm BO, Marselli L, Marchetti P, Stoffel M, Moch H and Spinas GA: Automated assessment of $\beta$-cell area and density per islet and patient using TMEM27 and BACE2 immunofluorescence staining in human pancreatic $\beta$-cells. PLoS One 9: e98932, 2014.

108. Ikeda K, Emoto N, Matsuo M and Yokoyama M: Molecular identification and characterization of a novel nuclear protein whose expression is up-regulated in insulin-resistant animals. J Biol Chem 278: 3514-3520, 2003.

109. Solimena M, Schulte AM, Marselli L, Ehehalt F, Richter D, Kleeberg M, Mziaut H, Knoch KP, Parnis J, Bugliani M, et al: Systems biology of the IMIDIA biobank from organ donors and pancreatectomised patients defines a novel transcriptomic signature of islets from individuals with type 2 diabetes. Diabetologia 61: 641-657, 2018.

110. Scott EM, Carter AM and Findlay JB: The application of proteomics to diabetes. Diab Vasc Dis Res 2: 54-60, 2005. 
111. Khan AR and Awan FR: Mining of protein based biomarkers for type 2 diabetes mellitus. Pak J Pharm Sci 25: 889-901, 2012.

112. Okada S, List EO, Sankaran S and Kopchick JJ: Plasma protein biomarkers correlated with the development of diet-induced Type 2 diabetes in mice. Clin Proteomics 6: 6-17, 2010.

113. Bustin SA and Mueller R: Real-time reverse transcription PCR (qRT-PCR) and its potential use in clinical diagnosis. Clin Sci (Lond) 109: 365-379, 2005.

114. Guénin S, Mauriat M, Pelloux J, Van Wuytswinkel O, Bellini C and Gutierrez L: Normalization of qRT-PCR data: The necessity of adopting a systematic, experimental conditions-specific, validation of references. J Exp Bot 60: 487-493, 2009.
115. Kim B: Western Blot Techniques. Methods Mol Biol 1606: 133-139, 2017.

116. Ule J, Hwang HW and Darnell RB: The future of cross-linking and immunoprecipitation (CLIP). Cold Spring Harb Perspect Biol 10: a032243, 2018

(i) (5) This work is licensed under a Creative Commons Attribution-NonCommercial-NoDerivatives 4.0 International (CC BY-NC-ND 4.0) License. 